\title{
Estudos de caso em Psicologia Clínica Comportamental
}

\author{
Silvares, E.F.M. (Org.) - Estudos de caso em psicologia clínica \\ comportamental. Infantil vol. II, Ed. Papirus, Campinas/SP. 2000.
}

atendimento a crianças é um assunto que provoca muito interesse em diversas áreas da psicologia. O estudo do comportamento infantil é expressivamente rico, devido às características peculiares que esta faixa etária apresenta. Deste modo evidenciase a importância do livro resenhado, que focaliza diversos estudos de caso em psicologia clínica comportamental infantil, de uma forma clara e bastante abrangente.

A partir de diversos temas pesquisados por diferentes profissionais, dos quais reconhecidos no meio acadêmico e evidente domínio acerca de sua linha de pesquisa, foi elaborada a obra em epígrafe, possibilitando aos estudantes e profissionais da área de psicologia um maior aprofundamento, acerca dos assuntos apresentados.

Organizado por Edwiges Ferreira de Mattos Silvares, professora e orientadora no programa de pós-graduação em psicologia clínica da Universidade de São Paulo-USP e também professora titular do Departamento de Psicologia Clínica do Instituto de Psicologia da USP, contanto com a participação dos demais colaboradores. Estruturado em nove capítulos, além da apresentação, o livro é composto por dois volumes, podendo ser lidos separadamente, devido ao seu caráter independente. Será apenas enfocado o segundo volume, por se tratar do volume mais recente.

Os temas são enumerados de acordo com as linhas de pesquisas específicas de cada um dos autores, visando à relação entre a teoria e a prática vivenciada neste tipo de atuação.

No primeiro capítulo, Maria Inês Monjas Casares e Vicente E. Caballo discutem o tema timidez infantil. Havendo uma introdução inicial, seguindo-se um estudo de caso, onde descrevem a utilização de estratégias de treinamento em habilidades sociais, além de outras intervenções de caráter cognitivo-comportamental, que remetem a um resultado bastante significativo, tendo em vista a efetivação do autocontrole e autonomia, apresentados ao final da intervenção.
Maria Cristina O. S. Miyazaki é a segunda colaboradora, abordando a depressão infantil, que atualmente é uma queixa bastante comum na infância. No estudo de caso é apresentado o atendimento de uma criança de nove anos, que sofre de depressão. Observa-se que o modelo cognitivo comportamental, associado à participação e empenho familiar, for bastante eficaz neste tipo de intervenção.

Enfocando a técnica de modificação de comportamento, Neide A. Micelli Domingos e Kelly Renata Risso, discutem no terceiro capítulo o transtorno de déficit de atenção e a hiperatividade infantil. Caracterizado por crianças impulsivas, desatentas, distraídas e impacientes. A introdução é bem detalhada, abordando os aspectos das possíveis causas, características, avaliação e formas de intervenções. As autoras dão um enfoque maior ao aspecto da elaboração criteriosa de um diagnóstico para uma intervenção adequada, considerando-se a dificuldade de identificação deste tipo de transtorno.

As considerações sobre encoprese infantil, tema do quarto capítulo, são realizadas por Yara Kuperstein Ingberman, e no capítulo subseqüente Diva Silva de Oliveira, Gabriel Tarragô Santos e Edwiges Ferreira Mattos Silvares, discorrem sobre a enurese infantil e o uso de alarme para seu controle. Ambos os capítulos são expressivamente detalhados, as introduções foram elaboradas de forma cuidadosa, visando a um entendimento preciso acerca do tema. As intervenções apresentadas remetem a resultados bem significativos, tendo em vista que com os estudos de casos ilustrados, evidencia-se a efetivação do controle sob o próprio corpo.

O tema agressividade infantil é abordado por Jaíde A. Gomes Regra, no sexto capítulo, que expõe o assunto de uma forma bastante objetiva, enfocando os diversos fatores que favorecem o aparecimento e manutenção do comportamento agressivo. $\mathrm{O}$ capítulo é enriquecido com estudos de casos, que abrangem as intervenções e o sucesso alcançado nos resultados. 
O Transtorno obsessivo compulsivo infantil é um tipo de transtorno pouco conhecido, o que dificulta o diagnóstico e tratamento adequado. Assim inicia-se o sétimo capítulo, escrito por Regina Christina Wielenska, que descreve como identificar e intervir, ressaltando que o êxito quanto à utilização de procedimentos comportamentais, pode ser alcançado, havendo a participação do paciente e sua família.

Dentro de uma perspectiva onde defende que, o processo de mudança do comportamento envolve ensino e aprendizagem, evidenciando que todo psicólogo é um educador. O oitavo capítulo escrito por Margarida $\mathrm{H}$. Windholz e Sonia B. Meyer, discorre sobre crianças com problemas de desenvolvimento e o nono capítulo escrito por Maria Martha Hübner e Miriam Marinotti, aborda as dificuldades escolares em crianças. Estes capítulos finais completam a obra, focalizando que a intervenção direcionada a crianças, tem um caráter especial, pois a cada objetivo alcançado, novos objetivos surgem, tornando-se um trabalho demasiadamente rico.

Cada capítulo é acompanhado pelas referências bibliográficas utilizadas, tratando-se de referências atuais, proporcionando ao leitor um maior aprimoramento acerca dos temas. A obra é bem organizada, com uma linguagem, de uma forma geral, objetiva e de fácil compreensão, oferecendo uma grande riqueza de informações, permitindo o contínuo interesse do leitor. Direcionada a estudantes, profissionais e estudiosos do comportamento infantil, a obra contribui para o desenvolvimento científico e prático do atendimento psicológico infantil.

Katya Luciane de Oliveira Aluna do Programa de Estudos Pós-Graduados em Psicologia da Universidade São Francisco - Itatiba 